Medicine Updates Faculty of medicine January 2022,volume 8 , issue 8 https://muj.journals.ekb.egdean@med.psu.edu.eg vice_dean_postgraduate@med.psu.edu.eg

DOI: 10.21608/muj.2021.98577.1074

ISSN : 2682-2741

\title{
" Applying of Quality Standards in Improvement of Patient's Nutrition in CCU in Al-Zohour Hospital] "
}

\section{$\underline{\text { Authors }}$}

Sameh Mahdy email 1; Heba Elsayed 2; Ahmed Alaa3; Wafaa Fathi4; Ahmed

Haggag3; Sanaa Abd Elmonem5; Noha Ali6; Doaa Hamdy7

1Pharmacist, Area manager of Yasser Hafny Pharmacies

$$
\text { 2Port Said University }
$$

3Anesthesiologist-Alzohour hospital

4Dermatologist-Elmansoura

5ICU nurse and member of quality team in Portsaid general hospital

6Physical specialist-El hayah hospital

7Family medicine specialist 


\begin{abstract}
:
A patient in the intensive care unit (ICU) has a variety of dietary difficulties. Patients admitted to critical care units may be hospitalized electively after major elective surgery or as emergencies following a surgical disaster, severe trauma, sepsis, or respiratory failure. The age range and previous health condition may vary greatly, and ICUs are now admitting a growing number of old, weak, or malnourished patients whose nutritional reserve may be seriously impaired. (1). The pursuit of relevant quality indicators for nutrition therapy (QINTs) is both fascinating and challenging.
\end{abstract} The goal of this study was to identify the QINTs that are most suited to the practice of quality control in nutrition therapy (NT) by analyzing the views of NT experts using psychometric methods and statistical tools. (2).

Secondary data were collected from Al-Zohor Hospital's adult ICU records. from 1 May 2020 to 3 June 2021 for this observational, cross-sectional, retrospective study.

QINTs that were ready for clinical use were evaluated in two stages. Nutrition experts evaluated QINTs in phase 1 by rating four characteristics On a 5-point Likert scale, rate usefulness, simplicity, objectivity, and low cost. The highest scores obtained were used to identify the top QINTs.

In order to be considered, the following conditions had to be met: being at least 18 years old and having had ENT, PNP, or both.

Men and women aged 18-65 years with a diagnosis of cancer were all evaluated, and they were supplemented with information required to assess quality indicators.(3)

In decreasing order, the top QINTs are:

1- the frequency of nutrition screening of hospitalized patients

2-diarrhea

3- Involuntary removal of enteral feeding tubes,

4- Obstruction of feeding tubes,

5- Fasting for more than 24 hours 
Dysglycemic

6-glycemic dysfunction

7-estimated energy consumption and protein requirements, 8-infection of a central venous catheter

9-compliance with NT indication, and 10-frequency of subjective global evaluation application.

The top QINTs were selected based on their clinical utility by achieving sufficient agreement and representativeness of nutrition specialists' opinions. (4)

\section{Kevwords:}

quality Standards , improvement nutrition ,healthcare

\section{Introduction:}

Nutrition therapy (NT) is critical for addressing protein-energy deficit and may help to prevent a variety of unfavorable outcomes, including an increased infection complication rate, worse wound healing, a longer hospital stay, higher treatment expenses, and increased mortality. (1) However, there are risks and side effects to NT, and it is governed by techniques that have been thoroughly developed based on important scientific publications in the area and professional agreement. . (2-5)

To guard against severe catabolism and avoid substantial deconditioning, critically sick patients need adequate dietary support to meet energy needs both during and after intensive care unit (ICU) admission ICU patients often have extended critical illness, which increases energy demand, resulting in proteolysis and muscle loss. Careful supplementation and calorie and protein intake control may aid in avoiding under- or overfeeding, both of which have been associated to worse outcomes. Indirect calorimetry is the most accurate method for measuring resting energy expenditure and the caloric and protein intake required to compensate for energy and muscle loss. Physical exercise has been proven to enhance muscle preservation and should be attempted as soon as a severely ill patient is admitted to the hospital. Oral intake should be carefully evaluated after 
being withdrawn from the ventilator or while on non-invasive ventilation and, in the case of severe dysphagia, avoided and replaced by enteral or parenteral nutrition. Appropriate nutrition is critical for long-term rehabilitation success after ICU discharge to the ward, and ongoing focus on adequate nutritional supplements in the ward is required to prevent a poor nutritional status. .(6)

ICU patients are admitted from their homes through the emergency department/operating room or from a hospital ward after a short or lengthy stay. Some of them are clearly malnourished as a result of a significant prior lack of appetite, weight loss resulting in varying loss of lean body mass, and/or numerous comorbidities, and they will generally need nutritional assistance. As a result, dietary intervention must be carefully planned and addressed at the same level as any other treatment supporting organ functioning in the ICU. Even if evidence for a clear benefit from early and targeted nutritional management is limited, reducing (further) malnutrition, as well as avoiding overfeeding and nutritional problems throughout the hospital stay, should be the goal for every patient in the ICU. (7)

Malnutrition still occurs often, affecting patient outcomes, bed turnover, and hospital expenditures. Nutritional treatment (TN) is a therapeutic option for nutritional recovery or maintenance when oral feeding is difficult or impracticable. Ensuring that nutritional treatment is prescribed and administered correctly is critical to avoiding metabolic and gastro-intestinal problems as well as conduct inconsistencies. Thus, the concept of integrating total quality management in patient care, allows for the identification and reduction of nonconformity between nutritional treatment predictions and everyday reality. As a result, all nutritional treatment patients should be regularly evaluated, and this assessment should guarantee assertive actions and low-cost clinical recovery . (8)

The goal of intensive care units (ICUs) is to provide healthcare to critically sick patients, and nutrition treatment is one tool in that armoury. (9) However, 
nutritional deficits are prevalent in this environment (10) RIBAS et al. (2014); GARCIA et al (2017)

Quality control in critical care is as essential as nutrition treatment. Quality indicators may help improve processes by evaluating their efficiency (10). Despite the lack of defined standards, the ILSI-Brasil Clinical Nutrition Taskforce has suggested a list of 36 indicators linked to nutrition treatment (11). Verotti et al. (2012) chose 10 top indicators from the ILSI-Brasil list as possibly relevant and useful. Other studies have addressed and utilised quality indicators, emphasising their relevance in continuing nutrition therapy quality evaluation. . (12).

We think that using quality indicators in nutritional treatment is beneficial (QINTs) is important and useful in assessing the quality of nutritional care, and that it should be carried out in accordance with the guidelines provided by the Joint Commission on Accreditation of Health Care Organizations and the Task Force of Clinical Nutrition at the ILSI - Brazil. Evaluating the quality of nutritional treatment enables dietitians to identify deviations from set objectives, which, when rectified, may ensure patients have access to the best nutritional therapy available. This method allows for the low-cost recovery/maintenance of nutritional status as well as the medium- and long-term enhancement of quality of life. There are many QINTs accessible for usage, and it is difficult for health professionals to specify the QINTs that will be used at each institution. There are no standard guidelines for choosing a QINT. (13).

\section{Aim of the work:}

find the problems in patient's nutrition in ccu in Alzohour hospital and try to solve them to increase patient survival rate.

\section{Methodologv:}

In research, methodology is described as the systematic process of resolving a research issue by collecting data using different methods, giving an interpretation of the data collected, and making conclusions about the study 
findings. A research technique is essentially the plan for a research or study. (14).

\section{Brain storming:}

team members' diverse experience into play. It increases the richness of ideas explored, which means that you can often find better solutions to the problems that you face.

In the presence of the team, We attempted to choose three objective and useful QINTs from among those already in use at El-Zohor Hospital that feature ease of execution (simplicity) and low cost.

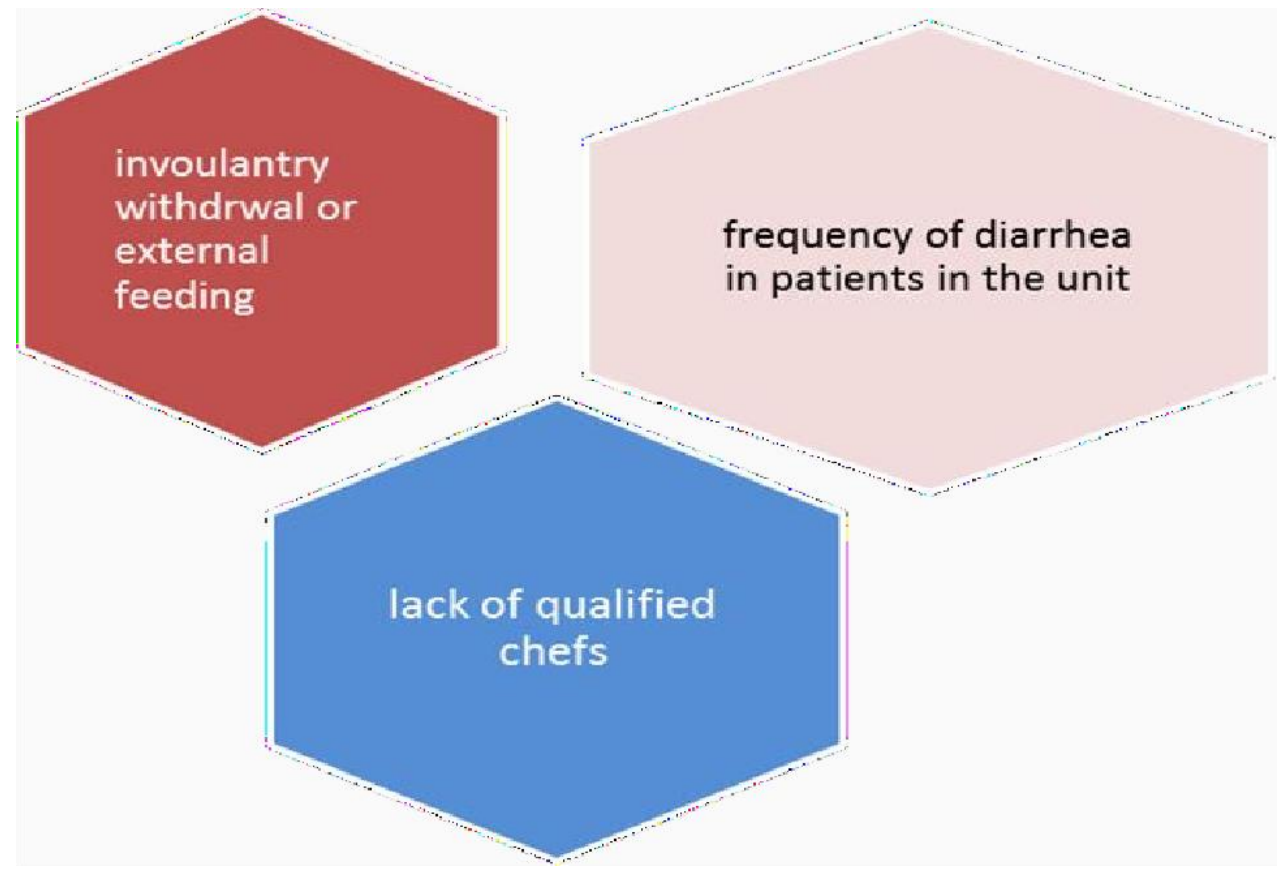

\section{$\underline{\text { Plan }}$}

human resource management to manage the quality of ccu we need to hire high quality employees because low quality hr leads to low quality patient service so we need to hire

nutritionist

infection control managers

trained chefs 
purchasing managers

\section{training and developing emplove}

frequent training for the employee

the (nutrionist, pharmacist, nursing, chiefs).

-A planned effort to enable the employee to learn job-related knowledge ,skills , and behavior.

-increase the employee's ability to meet changes in job requirement and patient demand.

-employ a person form infection control team to manage and monitor the hygiene and infection

nursing staff should frequently monitor the patient on tube feeding

-frequently monitor the blood sugar and vital blood tests

-financial management

-maximize the profits of the patient and minimize the cost by hiring a purchasing officer to get the best offers for food buying and monitoring machine

\section{Pareto chart:}

A Pareto Chart is a graph that indicates the frequency of defects, as well as their cumulative impact. Pareto Charts are useful to find the defects to prioritize in order to observe the greatest overall improvement

Secondary data were obtained from Al-Zohor Hospital's adult ICU records. from 1 May 2020 to 3 June 2021 for this observational, cross-sectional, retrospective study. 


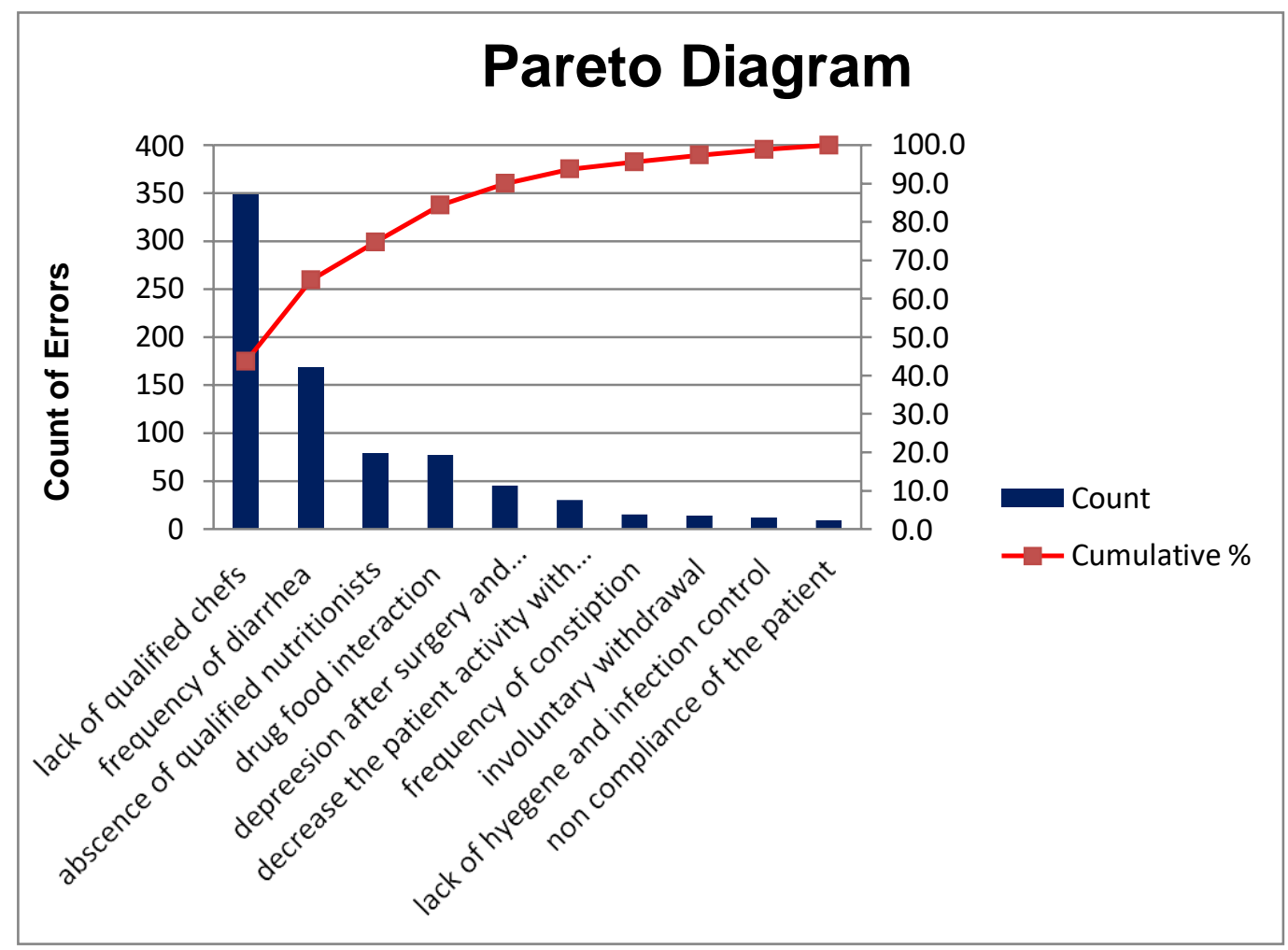

\section{The fishbone diagram}

As a homage to its inventor, the fishbone diagram is also known as the Ishikawa diagram. One of the seven quality circles (QC) tools is the fishbone diagram. It is beneficial to visualise possible reasons in order to identify the underlying cause of a certain issue. It aids in the identification, analysis, and improvement of quality problems. 


\section{Cause and Effect Diagram}

Quality Standards In Improvement Of Patient's Nutrition In CCU

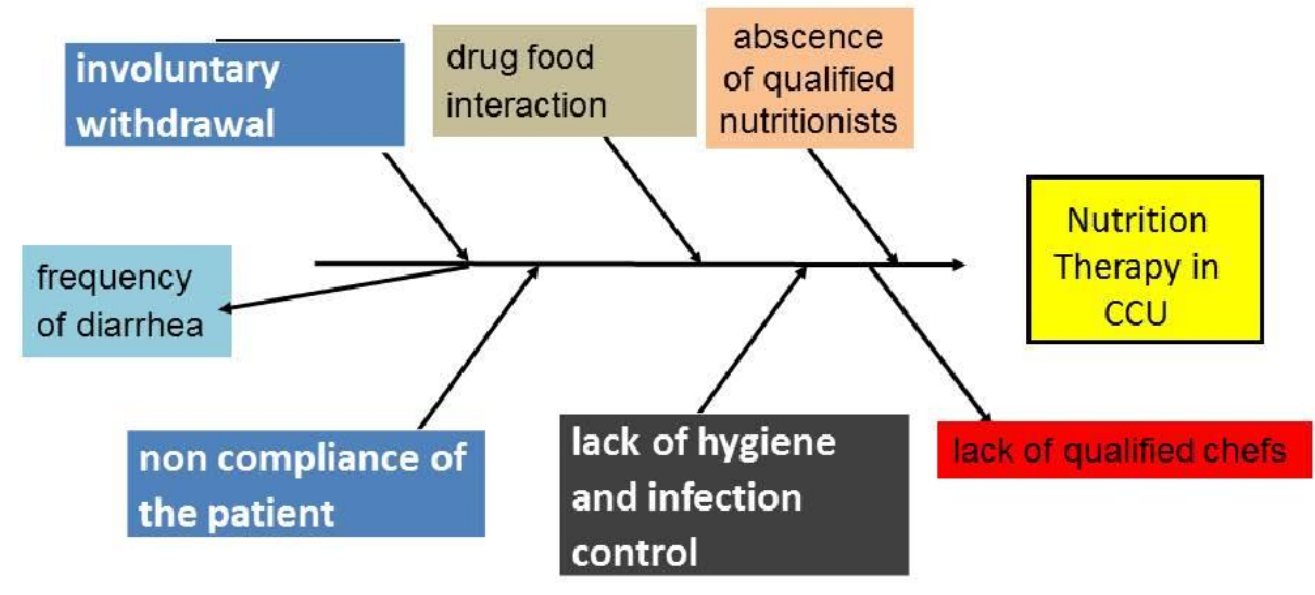

\section{Results:}

The structured questions from phase 1 revealed that the experts had comparable views on the QINTs examined.

Methods:

Secondary data were obtained from Al-Zohor Hospital's adult ICU records. from 1 May 2020 to 3 June 2021 for this observational, cross-sectional, retrospective study.

QINTs suitable for clinical use were evaluated in two stages. Nutrition experts evaluated QINTs in phase 1 by rating four characteristics (On a 5point Likert scale, rate usefulness, simplicity, objectivity, and low cost. The top QINTs were selected by the highest scores obtained. (Table 2)

Participants had to be at least 18 years old and had received enteral, parenteral, or both nutrition treatment. 
All the data needed to determine quality indicators were examined, including age gender diagnosis clinical result hospital stay duration.

At one point in the research period, 400 ICU patients , with $95(81.19 \%)$

fulfilling the inclusion criteria. (Table 1).

The top QINTs are listed in decreasing order.

1- the frequency with which hospitalised patients are screened for nutrition

2-diarrhea

3- Forced removal of enteral feeding tubes, 4- Obstruction of feeding tubes, 5- Fasting for longer than 24 hours

Dysglycemic Dysglycemic 6-glycemic dysfunction

8-infection of a central venous catheter, 7-estimated energy consumption and protein needs

9-NT indication compliance, and 10-frequency of subjective global assessment

Nutritional therapy (NT) is necessary for treating protein-energy deficit.

It may help to prevent a number of unfavorable outcomes, such as increased infection complication rates, delayed wound healing, longer hospital admissions, higher treatment costs, and increased death.

Protocol compliance may be monitored by doing periodic nutrition quality control to detect potential problems and failures related with protocol execution throughout the patient's nutrition treatment.

In addition to developing dietary guidelines (QINTs) must be developed to assess the appropriate application of these standards in NT.

Phase 1: The Best QINTs Have Been Selected The top 36 analyzed QINTs were matched into the following categories to determine the top QINTs(A) general considerations; (B) nutritional assessment; (C) NT indicator; and (D) 
preparation: pharmaceutical evaluation, modification, quality control, storage, and transportation; (E) administration: access methods; (F) administration: calories and proteins; $(\mathrm{G})$ clinical and laboratory monitoring; and $(\mathrm{H})$ final evaluation. .

\begin{tabular}{|l|l|}
\hline $\begin{array}{l}\text { Colum } \\
\text { n1 }\end{array}$ & Column2 \\
\hline $15 \%$ & lack of qualified chefs \\
\hline $11 \%$ & frequency of diarrhea \\
\hline $13 \%$ & abscence of qualified nutritionists \\
\hline $8 \%$ & drug food interaction \\
\hline $10 \%$ & $\begin{array}{l}\text { decrease the patient activity with coronary artry } \\
\text { illness }\end{array}$ \\
\hline $4 \%$ & frequency of constiption \\
\hline $11 \%$ & $\begin{array}{l}\text { infection might happen during perpartion } \\
\text { transportion alories intak inpatient with tube } \\
\text { feeding }\end{array}$ \\
\hline $7.60 \%$ & invoulantry withdrwal \\
\hline $70 \%$ & non compliance of the patient \\
\hline
\end{tabular}

Phase 2:

Nutrition Experts' Reactions

Concerning the one QINT chosen, prior experts and team members were questioned again to get their input by responding to two yes/no questions 
about the selection of QINTs and the list's consistency with their prior judgment .

Results:

Phase 1 structured questions revealed that the experts had similar viewpoints questioned regarding the characteristics of each of the QINTs evaluated.

Discussion:

This research aimed to identify three objective and helpful QINTs from among those presently in use at El-Zohor Hospital that include ease of execution (simplicity) and cheap cost.

1- lack of qualified chefs

2- frequency of diarrhea in patients in the unit

3- invoulantry withdrwal or external feeding plan:

1.human resource management;

to manage the quality of ccu we need to hire high quality employees because low quality hr leads to low quality patient service so we need to hire

- $\quad$ nutritionist

- $\quad$ infection control managers

- $\quad$ trained chefs

- $\quad$ purchasing managers

2.training and developing employee;

-frequent training for the employee the (nutrionist,pharmacist,nursing,chefs) 
-aplanned effort to enable the employee to learn job-related knowledge ,skills, and behavior)

-increase the employee's ability to meet changes in job requirement and patient demand .

- $\quad$ employe a person form infection control team to manage and monitor the hyiegne and infection

- $\quad$ nursing staff should frequently monitor the paient on tube feeding

- frequently monitor the blood sugar and vital blood tests

3.financial management ;

maximize the profits of the patient and minimize the cost by hiring a purchasing officer to get the best offers for food buying and monitoring machiens .

\section{Conclusion:}

The top QINTs were selected based on their clinical utility by achieving sufficient agreement and representativeness of nutrition specialists' opinions (16).

Prevention of adverse outcomes such as increased infection complication rate, poor wound healing, longer hospital stay, greater treatment costs and death may be achieved via nutrition therapy. . (17).

Protocol compliance may be monitored by doing periodic nutrition quality control to detect potential problems and failures related with protocol execution throughout the patient's nutrition treatment. (18).

Along with dietary guidelines, QINTs must be developed to monitor the proper implementation of these standards in NT.

By identifying non-compliances and suggesting remedial actions, this research helped ensure a sufficient delivery of nutrients, preserving or recovering the 
nutritional condition of critically sick patients. . (19).

Our research found that improving the food quality index is beneficial for patients' quality of life.

\section{Recommendations:}

Implementing quality standards in Nutritional monitoring was helpful in changing eating habits by lowering cholesterol, saturated fat, and salt intake. However, in terms of fat quality, there was a decrease in the consumption of monounsaturated fat while maintaining polyunsaturated fat intake in adults with no coronary disease, with 96 percent of patients having a poor diet and in need of improvement, a percentage much higher than that found in the current study.

Our findings should have been better for him to deal with individuals being treated for coronary artery disease secondary prevention.

\section{References:}

1- Barker LA, Gout BS, Crowe TC. Hospital malnutrition: prevalence, identification and impact on patients and the healthcare system. Int $J$ Environ Res Public Health. 2011; 8: 514- 527. CrossrefPubMedWeb of Science ${ }^{\circledR}$ Google Scholar

2- Lochs $\mathrm{H}$, Allison SP, Meier R et al. Introductory to the ESPEN Guidelines on Enteral Nutrition: terminology, definitions and general topics. Clin Nutr. 2006; 25(2): 180-186. CrossrefCASPubMedWeb of Science ${ }^{\circledR}$ Google Scholar

3- Guenter P. Safe practices for enteral nutrition in critically ill patients. Crit Care Nurs Clin North Am. 2010; 22(2): 197-208. CrossrefPubMedWeb of Science ${ }^{\circledR}$ Google Scholar

4- Singer P, Berger MM, Van den Berghe $G$ et al. ESPEN Guidelines on Parenteral Nutrition: intensive care. Clin Nutr. 2009; 28(4): 387- 400. CrossrefPubMedWeb of Science ${ }^{\circledR G}$ Google Scholar 
5- Heyland DK, Dhaliwal R, Day A, Jain M, Drover J. Validation of the Canadian clinical practice guidelines for nutrition support in mechanically ventilated, critically ill adult patients: results of a prospective observational study. Crit Care Med. 2004; 32(11): 2260- 2266. CrossrefPubMedWeb of Science ${ }^{\circledR G}$ Google Scholar

6- Critical Care, Volume 23 Supplement 1, 2019: Future of Critical Care Medicine (FCCM) 2018. The full contents of the supplement are available at https://ccforum.biomedcentral.com/articles/supplements/volume-23supplement-1

7- https://doi.org/10.1016/j.clnu.2018.08.037 0261-5614/@ 2018 European Society for Clinical Nutrition and Metabolism

8- (WAITZBERG,CUNHA and SALLUH; FRANCA, 2010)

9- Villet S, Chiolero RL, Bollmann $\mathrm{MD}$, et al. Negative impact of hypocaloric

feeding and energy balance on clinical outcome in ICU patients. Clin Nutr. 2005;24(4):502-509.

10- BRAUN, Jan-Peter; KUMPF, Oliver; DEJA, Maria; BRINKMANN, Alexander; MARX, Gernot; BLOOS, Frank; KALTWASSER, Arnold; DUBB, Rolf; MUHL, Elke; GREIM, Clemens; BAUSE, Hanswerner; WEILER, Norbert; CHOP, Ines; WAYDHAS, Christian; SPIES, Claudia. The German quality indicators in intensive care medicine 2013 - second edition. GMS German Medical Science, Berlim, v. 11, p. 1-17, July 2013. DOI: https://doi. org/10.1177/0884533611432317.

11- MARTINDALE, Robert G.; MCCLAVE, Stephen A.; VANEK, Vincent W.; MCCARTHY, Mary; ROBERTS, Pamela; TAYLOR, Beth; OCHOA, Juan B.; NAPOLITANO, Lena; CRESCI, Gail. Guidelines for the provision and assessment of nutrition support therapy in the adult critically ill patient: Society of Critical Care Medicine and American 
Society for Parenteral and Enteral Nutrition: Executive Summary. Critical Care Medicine, Mount Prospect, v. 37, n. 5, p. 1757-61, May 2009. DOI: 10.1097/CCM.0b013e3181a40116.

12- POULIA, Kalliopi-Anna; YANNAKOULIA, Mary; KARAGEORGOU, Dimitra; GAMALETSOU, Maria; PANAGIOTAKOS, Demosthenes B.; SIPSAS, Nikolaos V.; ZAMPELAS, Antonis. Evaluation of the efficacy of six nutritional screening tools to predict malnutrition in the elderly. Clinical Nutrition, Edimburgo, v. 31, n. 3, p. 378-85, Jun. 2012. DOI: https://doi.org/10.1016/j.clnu.2011.11.017.

13- Nutrition in Clinical Practice Volume 27 Number 2April 2012 261-267c 2012 American Society for Parenteral and Enteral Nutrition.

14- (Murthy \& Bhojanna, 2009, p. 32).

15- (Nutr Clin Pract). 2012;27:261-267.

16- AGARWAL, Ekta; FERGUSON, Maree; BANKS, Merrilyn; BAUER, Judith; CAPRA, Sandra; ISENRING, Elisabeth. Nutritional status and dietary intake of acute care patients: results from the Nutrition Care Day Survey 2010. Clinical Nutrition, Edimburgo, v. 31, n. 1, p. 41-7, Sept. 2012. DOI: . clnu.2011.08.002

17- BRAUN, Jan-Peter; KUMPF, Oliver; DEJA, Maria; BRINKMANN, Alexander; MARX, Gernot; BLOOS, Frank; KALTWASSER, Arnold; DUBB, Rolf; MUHL, Elke; GREIM, Clemens; BAUSE, Hanswerner; WEILER, Norbert; CHOP, Ines; WAYDHAS, Christian; SPIES, Claudia. The German quality indicators in intensive care medicine 2013 - second edition. GMS German Medical Science, Berlim, v. 11, p. 1-17, July 2013. DOI: org/10.1177/0884533611432317

18- BTAICHE, Imad F.; CHAN, Lingtak-Neander; PLEVA, Melissa; KRAFT, Michael D. Critical illness, gastrointestinal complications, and medication therapy during enteral feeding in critically ill adult patients. 
Nutrition in Clinical Practice, Bethesda, v. 25, n. 1, p. 32-49, Feb. 2010. DOI: 2F0884533609357565

19- CARTOLANO, Flávia De Conti; CARUSO, Lúcia; SORIANO, Francisco Garcia. Enteral nutritional therapy

KREYMANN, Georg. New developments in clinical practice guidelines. South African Journal of Clinical Nutrition, Lyttelton, v. 23, n. sup. 1, p. 2932, 2010. DOI: 